Nota Necrológica 


\section{NOTA NECROLÓGICA*}

\section{FALLECIMIENTO DEL HISTORIADOR TUNECINO, DESCENDIENTE DE MORISCOS ILMO. SR. SLIMANE-MÚSTAFAZBISS}

\section{BREVE SEMBLANZA}

Slimane-Mústafa Zbiss ha fallecido repentinamente, a los 90 años de edad, en Túnez (14 de mayo de 2003). Había nacido el 30 de abril de 1913 en la pequeña ciudad de Testur (Tunicia), capital comarcal de unos pueblos que fueron rep oblados por moriscos expulsados de España hacia 1609-1614 y llamados andalusíes (de Al-Ándalus, evidentemente) en su nueva patria. En esas poblaciones tunecinas, a unos $80 \mathrm{kms}$. al oeste de la capital y a la orilla del único río importante de Tunicia, el Medjerda, aún conservan apellidos, expresiones, recetas alimenticias y otras costumbres de origen español. Testur es la capital tunecina de la música andalusí, con su festival anual, en julio; el Sr. Zbiss fue siempre experto promotor de la música andalusí ( $m a$ ’lûf) y presidió durante varios años la asociación musical Rashidiyya, de música andalusí, en Túnez. Él y su familia llevan un apellido que creen de origen valenciano-catalán (Llop is) o granadino (Chapiz).

Durante largos años responsable de diversos dep artamentos dependientes del Ministerio de Cultura, estudió en particular los restos hispánicos conservados aún en Tunicia (especialmente los arqueológicos, onomásticos y etnológicos) con sus discípulos, en especial su hija la Sra. Nabila Zbiss (etnóloga) y el Dr. Abdel-Hakim Slama Gafsi (historiador y arqueólogo). El Sr. Zbiss dedicó toda su vida profesional, especialmente después de su jubilación, al estudio del patrimonio cultural tunecino. Había sido bibliotecario de la sección de manuscritos de la Biblioteca Nacional de Túnez, arqueólogo del ahora Instituto Nacional del Patrimonio, Director General del Servicio Nacional de Antigüedades, fundador y director del Centro de Estudios Hispano-Andalusíes del Ministerio de Cultura, escritor de numerosos libros y estudios, académico correspondiente de la Academia de la Historia de Madrid, etc.

Había sido objeto de numerosos homenajes, entre los que destacan:

Fue nombrado Académico correspondiente de la Academia de la Historia, de Madrid, por iniciativa del Embajador de España y escritor Alfonso de la Serna, en 1970.

Este estudio se ha realizado en el marco del proyecto de investigación Edición digital de los textos en español de los mudéjares y moriscos y su contexto historiográfico, con la referencia BFF2002-02497, del Plan Nacional de Investigación Científica, Desarrollo e Innovación Tecnológica, cofinanciado con FEDER y concedido en el año 2002. 
Invitado por el científico español y Premio Príncipe de Asturias Alberto Orts, fue objeto de un homenaje en 1985, en el marco de las fiestas de moros y cristianos de Sax (Alicante), invitado por su Excmo. Ay untamiento, y dio con esta ocasión una conferencia en la Universidad de Alicante. Inauguró en 1990 el Monument al Morisc Expulsat, sito en el Port de Sant Carles de la Ràpita (antiguo Port dels Alfacs, por donde fueron expulsados moriscos aragoneses, catalanes y valencianos), con ocasión del Congrés Internacional sobre «L’Expulsió dels Moriscs».

Con ocasión de su 85 aniversario había sido objeto de un grueso volumen de Homenaje internacional, publicado por el Instituto Nacional del Patrimonio, de Túnez (2001), en el que particip aron diversas personalidades científicas de sus especialidades investigadoras (entre ellos 6 españoles: L.-F. Bernabé Pons, M. de Epalza, F. Franco Sánchez, de la Universidad de Alicante; J.-B. Vilar y M.J. Vilar, de la Universidad de Murcia; A. Sanmiguel Mateo, Director del Servicio Arqueológico de Calatayud) [ver reseña del volumen en ALJAMÍA, vol. 15, año 2003, págs. 355-358.].

Fue objeto de una exposición de su obra, en la televisión tunecina y en la valenciana, y de una entrevista personal digitalizada, realizada por el Dr. Slama-Gafsi y presentada en el IX ${ }^{\mathrm{o}}$ Simposio Internacional de Estudios Mudéjares, en Teruel (2002). Esa larga entrevista sobre sus estudios y publicaciones está “on line” en Internet desde 2001, por iniciativa y a petición de la catedrática de árabe Dra. María Jesús Rubiera Mata, directora del portal «Literatura de Mudéjares y Moriscos» de la Biblioteca Virtual Miguel de Cervantes Saavedra, de la Universidad de Alicante (http: //cervantesvirtual.com / portal / lmm).

El sábado 10 de may o de 2003 recibía un homenaje por sus 90 años y por su restauración del Ribat en la ciudad costera de Monastir, con la participación del Ministro de Cultura de Túnez, Dr. Hermassi. Dos días después, tras un desayuno en que comentaba con alegría las anécdotas del homenaje de Monastir, caía fulminado por un ataque repentino que le llevaría al fallecimiento, dos días después. Las ceremonias fúnebres de los arbaín, a los 40 días de su muerte, serían una ocasión más para hacer en Túnez un nuevo homenaje a ese personaje notable de la cultura nacional tunecina.

El Sr. Zbiss fue también objeto de un homenaje especial el 28 de mayo, en la inauguración de la exposición «Tunísia. Terra de Cultures», organizada por el Institut Europeu de la M editerrània, en el Salón medieval del Tinell, en el Barrio Gótico de Barcelona. Esta exposición se abrirá también en Valencia, en septiembre 2003, y en otras ciudades del Mediterráneo, organizada por la Xarxa de Museus de la Diputació de València, junto con el Ministerio de Cultura de Túnez. Ha dado origen a un volumen científico muy bien ilustrado, en catalán y en inglés, Tunísia terra de cultures, land of cultures, publicado por el Institut Europeu de la M editerrània (Barcelona, 2003), con un catálogo de las piezas y diversos capítulos monográficos (de 18 investigadores tunecinos y 5 españoles).

\section{PRINCIPALES PUBLICACIONES DEL SR. ZBISS SOBRE MUDÉJARES Y MORISCOS}

\section{LIBROS SUYOS}

Al-atāar al-islämiyya fī 'ahd al-atrak [“Los monumentos islámicos de época turca”], Túnez, 1955 [diversas ediciones, en árabe y en francés] Atāar ad-dawla al-ḥusayniyya bi-l-qutr at-tūnis $\overline{1}$ [“Los 
monumentos de la dinastía husainí en el territorio tunecino”], Túnez, 1955 [diversas ediciones, en árabe y en francés]

Naqā'iš Tūnis wa-ahwāzi-hā [“Inscripciones de Túnez y sus alrededores”], Túnez, 1955 [cinco volúmenes, en árabe y en francés, entre 1955 y 1977, de Túnez, de Monastir y de Qayrawán]

Buyūt 'adana Al-lahu an turfa'u [“Edificios que Dios permitió se alzaran” -mezquitas-], Túnez, 1968.

Al-qibảb at-tūnisiyya fī tatawwuri-hā [“Las cúpulas tunecinas y su evolución”], Túnez, 1968.

\section{LIBROS COORDINADOS POR ÉL}

Zbiss, Slimane - Mostafa - Gafsi, Abdel-Hakim - Boughanmi, Mohiedine - Epalza, Míkel de (edits.), Études sur les Morisque Andalous, Túnez, ed. Institut National d'Archéologie et d'Art (col. Études Hispano-andalouses, 2), 1983, 283 pp. [en español y francés] + 108 pp. [en árabe].

\section{ARTÍCULOS DE REVISTAS CIENTÍFICAS O CAPÍTULOS DE LIBROS}

«Tūnis wa-l-hadāra al-andalusiyya [“Túnez y la civilización andalusí”], Maŷalla tārīj al-‘arab wa-l-‘alam, Líbano, marzo 1972, 23-29.

«Présence espagnole à Tunis», en Míkel de Ep alza - Ramón PetiT, Recueil d'études sir les Morisques Andalous en Tunisie, Madrid, ed. Ministerio de Asuntos Exteriores, 1973, 267-270.

«Ass-sawma“āt bi-madīna Tūnis [“Los minaretes en la ciudad de Túnez”]», Maŷalla al-fann fī-l-islām [“Revista del Arte en el Islam”], (Roma), febrero 1976, 12-18.

«Ŷ̀ami“ balad Sulaymān [“Lamezquita del pueblo de Solimán”]», Ma ŷalla al-Hidāya (Túnez), sept. 1977, 71-75; reproducido en ZBISS - GAFSI - Boughanmi - EpALZA (1983), 39-48 (parte en árabe).

«Quelques sites andalous de Tunisie», Awrâq (Madrid), I (1978), 55-58.

«Ŷāmi‘ Binzart al-kabīr [“La Mezquita Mayor de Bizerta”]», Maŷalla al-Hidāya (Túnez), julio 1980, 76-79, 85.

«Barnāma ŷ Ibn Ŷabir al-Wādī Āšī Al-Andalusī at-Tūnisiyya. As-Ṣirā' al-‘aqa'idī fī al-falsafa al-islāmiy y ["La parte tunecina del Barnämaŷy de Ibn Ŷabir de Guadix El Andalusí. El combate doctrinal en la filosofía islámica”]», 74 Coloquio de Monastir, Túnez 1978, 100-107.

«Al-ŷāmi` al-kabīr bi-Ṭaburba [“La Mezquita May or de Teburba”]», Ma ŷalla al-Hidāya (Túnez), enero 1983, 43-46. 
"Apports des morisques andalous en matière d'agriculture, en Tunisie», en Abdeljelil TEMIMI, (edit.), Religion, Identité et Sources Documentaires sur les Morisques Andalous, Túnez, ed. Publications de l’Institut Supérieur de Documentation (nº 4), 1984, II, 201-211.

«Brillante carrière en Tunisie de deux grands savants valenciens: Abū al-Mutarrif ibn Amīra et Muhammad ibn al-Abbār», en EpalzA, Míkel de - Huguet, Jesús (coords.), Ibn al-Abbar. Polític i escriptor àrab valencià (1199-1260). Actes del Congrés Internacional "Ibn Al-Abbar i el seu temps ”. Onda, 20-22 febrer 1989, València, ed. Generalitat Valenciana (Col-lecció Fonaments, 3), 1990, 99-106.

ZBiss, Slimane M ostafa - SlAma GAFSI, Abdel-Hakim - EpAlZA, Míkel de, «Entrevista al Sr. Zbiss realizada p or Abdel-Hakim Slama Gafsi», Biblioteca Virtual «Miguel de Cervantes Saavedra», Alicante, 2001.

Zbiss - Slama-Gafsi - Epalza (1983) : ZBiss, Slimane - Slama Gafsi, Abdel-Hakim - EpalZA, Míkel de, (2002), entrevista en vídeo a Zbiss en francés, realizada por Slama-Gafsi en 2001 y transcrita, traducida y adaptada para el portal de internet de Rubiera (2002), en prensa en actas de IX Simposio de Estudios Mudéjares y en la revista Sharq Al-Andalus. Estudios Mudéjares y Moriscos, Universidad de Alicante - Centro de Estudios Mudéjares.

[La mayor parte de estos datos bibliográficos están tomados del volumen de homenaje Dirāsāt $f \overline{1}$ al-atār wa-l-naqā'iš wa-t-tārīj, takrīman li-Sulaymān Muștafà Zbis. Mélanges d'archéologie, d'épigraphie et d'histoire offerts à Slimane Mustapha Zbiss, Túnez, ed. Institut National du Patrimoine, Ministère de la Culture, République Tunisienne, 2001, 161-165 (bibliografía del homenajeado)].

Míkel de EPALZA 